\title{
GEORGE W. HILL, CLASS OF 1859
}

\section{BY ALBERT E. MEDER, JR.}

Vice Provost and Dean of the University, Rutgers University

W

HEN Rutgers celebrated its I 75th Anniversary in 194I, a series of Convocation Lectures was held, one of which was addressed by a distinguished mathematician and astronomer. An undergraduate leaving the Gymnasium was overheard summing up the lecture in the following words: "G. W. Hill was a great man, and the universe is orderly." The summary of the lecture was accurate; so was the lecturer's characterization of Hill.

George William Hill was indeed a great man. He held honorary degrees not only from his alma mater, Rutgers, appropriately the first institution to grant such recognition to Hill, but also from Columbia, Princeton, and Cambridge. He was elected an honorary member or a foreign correspondent of the Royal Astronomical Society, the Cambridge Philosophical Society, the Manchester Literary and Historical Society, the British Association for the Advancement of Science, the Royal Society (London), the Institut de France (section of astronomy of the Academie des Sciences), the London Mathematical Society, the Royal Society of Edinburgh, the Bavarian Academy of Science, the Society of Science in Christiania (now Oslo), the Calcutta Mathematical Society, the Swedish Academy of Science, and the Italian Accademia dei Lincei.

He received the Gold Medal of the Royal Astronomical Society, the Bruce Gold Medal of the Astronomical Society of the Pacific, both French and Russian monetary prizes, and the Copley Medal of the Royal Society, London, commonly regarded as the highest British scientific honor.

Hill was a member of the National Academy of Science and of the American Philosophical Society. He was the third President of the American Mathematical Society, I 895-I 896; not for thirty years would there be another mathematician in the presidential chair who equalled Hill in the extensive international recognition of his eminence.

Hill's greatness is also made evident by the persons with whom his name was associated. Only mathematicians will fully appreciate 
the significance of the rest of this paragraph, but even the uninitiated will surely sense its import. When Hill was elected to honorary membership in the Cambridge Philosophical Society, those elected with him included Willard Gibbs, Kronecker, Lie, and Poincaré. When he was elected to honorary membership in the Calcutta Mathematical Society, the list included also Osgood, Darboux, and Picard. The three presidents of the American Mathematical Society whose collected works have been published are Hill, Birkhoff and von Neumann. A ranking made in 1903 of living American mathematicians listed E. H. Moore, G. W. Hill and W. F. Osgood as the first three, in that order. If greatness is in part at least reflected by association, no higher confirmation could be found than these names.

The biographical facts of Hill's life are simple. Born in New York City on March 3, I838, the son of an artist of considerable distinction, of English and Huguenot ancestry, he was graduated from Rutgers College in I 859; he was associated with the Nautical Almanac Office for thirty-one years, retiring in 1892 at the age of 54 , and thereafter living on the family farm in West Nyack, New York, where he continued active scientific research and publication until his death in West Nyack on April I6, I 9 I 4. He never married.

Approximately one-half of Hill's scientific research was produced after he left the government service, and most of his honors were received in the same period of his life. His one excursion into academic life also took place while he was living at West Nyack; he lectured on Celestial Mechanics at Columbia University for two two-year periods.

Scientifically, Hill can be characterized only as remarkable. $\mathrm{He}$ has been competently described as "easily ... the greatest master of mathematical astronomy during the last quarter of the nineteenth century." Among the alumni of Rutgers, he stands alone in his field; no other graduate in mathematics or astronomy comes even close to Hill's eminence.

His first published paper appeared before his graduation from Rutgers. It is entitled: "On the Curve of a Drawbridge." But his second paper, published a year after graduation, has to do with mathematical astronomy, and thereafter hardly a year passed without several publications by him in this field, up to the year of his death. 
As might be expected, the earlier publications betray the computational interests of the Nautical Almanac. But even in his first few years in the Nautical Almanac Office, Hill's publications dealt with theoretical as well as practical subjects.

His fame among mathematical astronomers rests on two major contributions, one published privately in 1877 and the other in Volume I, Number I of the American Journal of Mathematics in I 878. The latter is entitled, "Researches in the Lunar Theory," and is important as much for the further work it stimulated as for its own content. E. W. Brown, first Josiah Willard Gibbs Professor of Mathematics at Yale University, called this memoir of Hill's "fundamental for the development of celestial mechanics in three different directions," and observed that "it would be difficult to say as much for any other publication of its length in the whole range of modern mathematics, pure or applied." Poincaré, a mathematician of unquestioned eminence whose name would be included with Archimedes and Gauss in anyone's list of "all-time greats," remarked that in Hill's memoir we may perceive the germ of all subsequent progress in celestial mechanics.

The earlier memoir is more significant for the light it sheds on Hill's own powers. In his discussion he is led to a second order differential equation now known as "Hill's equation" and so referred to in the literature. This equation is equivalent to an infinite number of algebraic linear equations. By entirely original and elegant methods, Hill showed how to develop the infinite determinant corresponding to these equations, and from it calculated the unknown correct to fifteen places of decimals. He reduced the determinant to a convergent form, but he did not prove convergence.

Mathematicians will agree from what has been said-and nonmathematicians may well accept the fact-that Hill's formulation and solution of this equation reveals mathematical power of no mean order, ability to deal with both pure and applied mathematics, and a clearly overriding interest in the latter.

One other important achievement of Hill should be mentioned. Simon Newcomb, Superintendent of the Nautical Almanac Office from I 877 to I 897 , and incidentally, Hill's immediate successor as President of the American Mathematical Society-probably a better known astronomer than Hill, but by no means the mathematician 
that Hill was-set himself the enormous task of preparing a collection and comparison of all known planetary observations. This was published in I 897 under the title, Elements of the Four Inner Planets and the Fundamental Constants of Astronomy. The most difficult part of this work involved the motions of Jupiter and Saturn. This problem-and it was not merely a clerical or computational problem - was turned over to Hill, who spent ten years on the work. Without Hill's important contributions, Newcomb's work could not have been completed.

While Hill was clearly possessed of a single-minded devotion to celestial mechanics, he had other hobbies. He was particularly interested in nature: trees, flowers, and birds; and he loved to walk. It is said that the whole countryside for miles around both Washington, D.C., and Nyack, New York, was an open book to him. He made two camping expeditions to northwest Canada, going by canoe from Lake Superior to Hudson Bay and back. Though inherently shy, he was nevertheless friendly and cheerful.

Of the thirty-one young men who received the Degree of Bachelor of Arts in Rutgers College in 1859, George William Hill was the only one who entered upon a scientific career.

The occupations of 30 of the Class are recorded in Dr. Raven's Catalogue. ${ }^{1}$ There are I 5 clergymen, I I lawyers, I physician, I broker, I manufacturer (of wall paper) and I mathematical astronomer. Clearly Hill must have had natural talents and aptitudes that led him to his career. But almost certainly these flourished because of some influence exerted upon him during his college years.

The influence is not hard to identify. It was exerted by Theodore Strong, Professor of Mathematics and Natural Philosophy from I 827 to 1863 .

From the viewpoint of the present day, a person less likely to influence the development of a great mathematician could hardly be conceived. Strong had had no formal training in mathematics beyond his Yale A.B., and was in his late sixties at the time Hill came into his classes. But times were different then, and formal advanced work was not essential. Indeed, Hill himself had no formal study beyond his A.B.

1 W. H. S. Demarest, A History of Rutgers College, r766-rg24 (New Brunswick, I 924$)$, p. 376 . 
Theodore Strong was a charter member of the National Academy of Sciences, was commonly regarded as an outstanding mathematician by his contemporaries, and did indeed publish widely, as publication was understood in those days. He had been graduated from Yale in $18 \mathrm{I} 2$; he was appointed immediately to the staff of a new institution, Hamilton College, where he remained until i 827 , when he resigned to accept appointment at Rutgers to the professorship vacated by Robert Adrain, America's first mathematician with any claim at all to distinction in research. Strong was in fact a worthy successor; no further evidence is needed than the fact that Hill's mathematical education was shaped by Strong.

Strong's secret weapon was one that has been employed (and still is) by many professors skilled in the development of young mathematicians. It is to refer them to the great classical treatises of mathematics. That was how Strong had developed himself as a mathematician; that was how he developed Hill. Obviously his influence could not have been exerted in any real sense through the rigid curriculum and the conventional classroom of the day. Indeed $\mathrm{Mr}$. Justice Joseph P. Bradley in his memorial address concerning Theodore Strong before the National Academy tells us that Strong's teaching was not highly regarded by the average student, but was greatly esteemed by those of talent in his field.

That Hill so regarded Strong is well documented, not least by the statement of Doctor W. H. S. Demarest that Hill had told him "that he received his great impulse to searching and enduring mathematical and astronomical study from Professor Strong and ... that the faculty as a whole were rather out of sympathy with him because he wished to pass the bounds of the curriculum and explore the learning beyond."2

Hill did certainly explore the learning beyond, so successfully that he is without doubt the greatest mathematical scholar Rutgers has produced in its two hundred years, so modestly that many Rutgers graduates and faculty members do not know his name. Indeed there are two pertinent stories extant on this point.

One has to do with the Rutgers faculty member who in answer to a question was naming distinguished Rutgers alumni. Reproached for

2 Demarest, p. 376. 
his omission of Hill, whose name was known to his questioner, he had to confess that he had never heard of him.

The second has to do with an American professor appointed to lecture at the Sorbonne. At the customary welcoming dinner, he was embarrassed by a speech welcoming him for the conventional reasons, including his own accomplishments, but chiefly because he was a countryman of George William Hill!

Even Hill's own brother said that George knew nothing except astronomy, and evidently the latter had no conception of how much George knew about that, and of how much of that which he and others knew, he had himself developed.

One of the few-and it is known that they were in fact very few-persons who attended Hill's Columbia lectures was a young graduate student, who forty years later, having then become eminent took it on himself to ferret out Hill's home in West Nyack and to place thereon a bronze tablet inscribed as follows:

\author{
GEORGE WILLIAM HILL \\ I 838-I 9 I 4 \\ ASTRONOMER MATHEMATICIAN \\ LIVED IN THIS HOUSE
}

Surely this says something about the greatness, the influence, the modesty of the man.

Whether or not the universe is truly orderly may be debatable, but that G. W. Hill was a great man is not. 


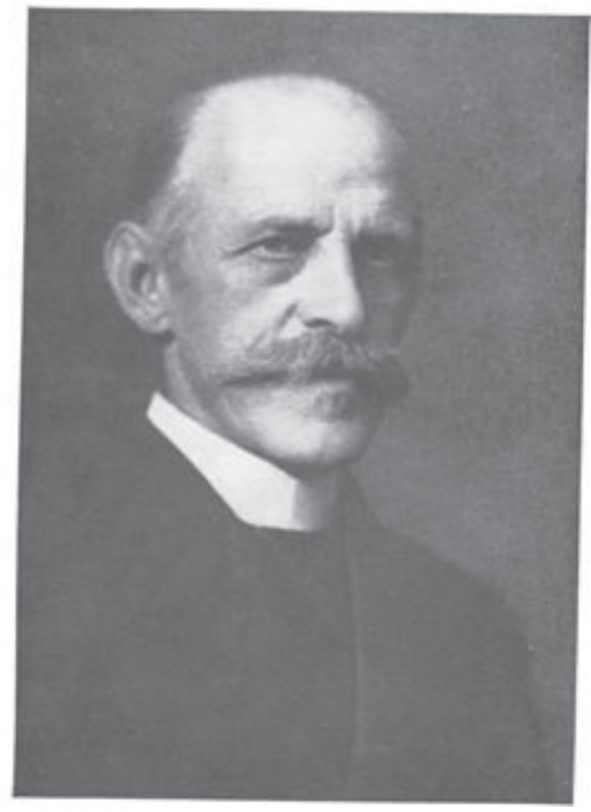

William Ellio'T Griffis I $843-$ I 928
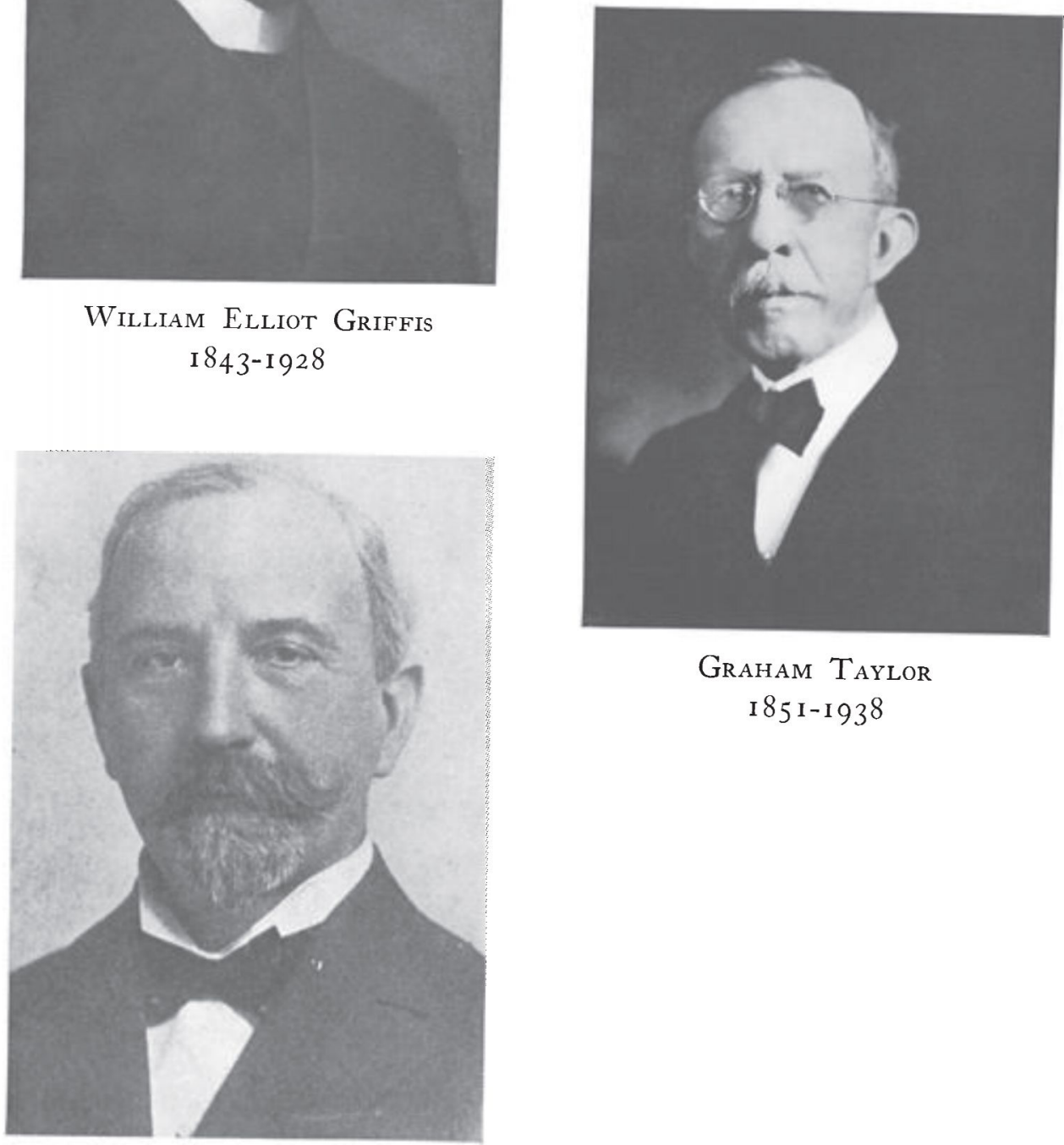

Graham Taylor I 85 I - I 938

Albert Stanburrough Cook I $853-1927$ 